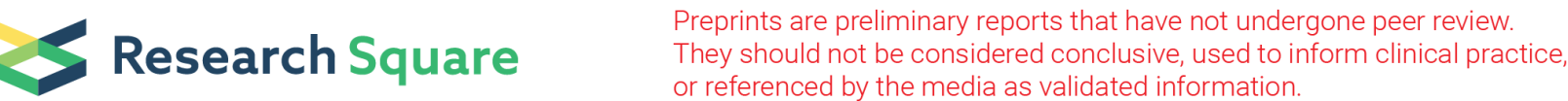

\section{Intragenerational Social Mobility and Preventive Behaviors regarding COVID-19: A Case Study of the Slum and Non-Slum People in Dhaka City}

Abul Kalam Azad Azad ( $\sim$ kalamazad@bup.edu.bd)

Bangladesh University of Professionals

Anika Nowrin Khan Mohinee Mohinee

Bangladesh University of Professionals

Shamme Akter Shamme

Bangladesh University of Professionals

Md. Tanvir Mahtab Tanvir

Bangladesh University of Professionals

Md. Hafiz lqbal, PhD Hafiz

Government Edward College, Pabna

\section{Research Article}

Keywords: Intragenerational social mobility, socioeconomic status index, perception gap index, COVID-19 pandemic

Posted Date: September 10th, 2021

DOI: https://doi.org/10.21203/rs.3.rs-882191/v1

License: (1) This work is licensed under a Creative Commons Attribution 4.0 International License.

Read Full License 


\section{Abstract}

Background: The policy design for eliminating health inequality from social mobility perspective has been prioritized in the sociological studies. The World Economic Forum has also developed Global Social Mobility Index taking into account the fixing of social inequality including health inequality. Unfortunately, the policy design and explanation for preventive behavior gap regarding COVID-19 from social mobility perspective has hitherto been an unexplained phenomenon in Bangladeshi context. This study, hence, evaluates the effectiveness of Health Belief Model (HBM) in explaining the preventive behavior gap index (PBGI) regarding COVID-19 in relation to Blau and Duncan's socioeconomic status (SES) index and explores other extraneous factors.

Methods: The study follows explanatory sequential mixed-method approach. In the first phase, the study has conducted pilot test for confirmatory factor analysis. The second phase is also quantitative in nature which follows the perfectly experimental research design. In this regard, the study first used SPSS software (Windows version 25) and then converting into CSV format linked with SmartPLS 3 for developing structural equation model. In the third phase, qualitative data were collected using key informant interview to explore other extraneous factors that can explain the preventive behaviors of slum and non-slum peoples of Bangladesh regarding COVID-19.

Results: The high SES index score of non-slum people have positively significant effect on their PBGI regarding COVID-19 mediated through perception gap index (PGI) while the low SES index score of slum people have negatively non-significant effect on the same constructs.

Conclusions: The HBM as dysfunctional should be revisited in line with the free provision of protective equipment for understanding the health behavior of those people who live from hands to mouth.

\section{Background}

Coronavirus disease 2019 (COVID -19) is an emergent public health pandemic, which is running its statistical play on the wave of human infection and death in an unpredictable way all around the world. Sometimes its direction is downward while other times upward as it were a music. [1] identified this COVID-19 as the product of the severe acute respiratory syndrome, coronavirus 2 (SARS-CoV-2). On 4 March 2020, the Institute of Epidemiology, Disease Control and Research (IEDCR) has cautioned about the risk situation of Bangladesh in terms of connectivity, belief, knowledge, and attitude of people between rural and urban, rich and poor, literate and illiterate, men-women, and slum and non-slam [2]. The observational studies find that preventive behavior gap index (PBGI) regarding COVID-19 is the product of knowledge and attitude. For instance, the PBGI regarding COVID-19 is affected by knowledge, gender, attitude, and practice [3, 4]. Male, divorced or widowed, alcohol consumers, smokers, village dwellers, and less educated people make hindrance for minimizing the preventive behavior gap in COVID-19 [5]. Knowledge, perceived susceptibility, perceived benefits and perceived self-efficacy are significantly associated with COVID-19 related PBGI in China [6]. According to [7, 8, 9], knowledge, perceptions, and 
health beliefs are potential contributors to COVID-19 related PBGI. The empirical studies also support the HBM constructs including susceptibility, severity, benefits, barriers and self-efficacy [10]. The previous study findings related to the determinants of PBGI regarding COVID-19 are not identical. This is the shortcoming of those studies to understand why the PBGI regarding COVID-19 significantly varies from Western developed world to developing countries like Bangladesh. Even, in the context of Bangladesh, some studies reveal that knowledge, attitude and practice (KAP) model is effective while other studies find the opposite result. In fact, the related existing studies could not understand the developed nations are directed toward the upward social mobility, universalism and achievement while Bangladesh is in the stage of particularism, ascription and many communities in the country are still now directed toward downward mobility. At the same time, affluent families or communities of Bangladesh are directed toward upward mobility. Thus, merely knowledge and perceived health beliefs fail to predict or explain PBGI regarding COVID-19. Rather, the social class or strata may matter in the societies. Hence, the study has an endeavor to evaluate the usefulness of HBM in explaining the PBGI regarding COVID-19 among the slum and non-slum people of Bangladesh depending on the constructs of HBM in relation to socioeconomic status (SES) index of [11].

\section{Theoretical Framework}

\section{Health belief model (HBM)}

The HBM was first developed in the 1950s- by social psychologists of the U.S. Public Health Service to explain the failure of disease preventive programs [12]. This model has 5 core constructs: perceived severity (beliefs about severe and consequences of the condition), perceived susceptibility (beliefs about magnitude of the possibility to be exposed/suffering from the condition), cues to action (contributing to perceived threat), perceived benefits (belief about the usefulness of taking a particular action), perceived barriers (negative belief of taking a particular action) [13] The perceived severity, susceptibility and cues to action taken together refer to perceived threat [14]. Recently, the perceived self-efficacy is added with HBM as another construct [10]. The degree of effectiveness and magnitude of such constructs are not same. For instance, perceived susceptibility explained health behavior better for prevention than treatment while the opposite was true for perceived benefits and perceived severity [15]. In this viewpoint, the HMB is not affected by the perceived barriers and the cues to action is rarely considered as a determinant of HBM [16]. Observational literature suggests that inclusion of few modifying factors such as socio-demographics, socio-psychological and structural variables in the HBM are essential for assessing the beliefs, perception and the likelihood of preventive behavior of a certain disease $[12,14]$.

However, there are numerous criticisms and inconsistencies of effectiveness of HBM when the sociostructural variables are not properly addressed. Inclusion of such variables in the HBM are essential for assessing personal behavior like immunization behavior and risk practices [17]. Based on the guideline of SES index of [11], we considered few socio-economic variables in our proposed model that are explained in the following. 


\section{Model specification}

We specified the hypothesized model of PBGI regarding COVID-19 (see Fig.1 for more details). Under this model, we include other extraneous factors for proper understanding of health behavior for slam and nonslum people in Dhaka city.

In Fig 1, SES stands for Socioeconomic Status; MOBIN stands for mobility index based on education, occupation and income; PGI signifies perception gap index; PBGI stands for Preventive Behavior Gap Index; EDUs means educational levels of slum people; OCCs means occupational categories of slum people; INCs means the monthly income of slum people; EDUns means educational levels of non-slum people; OCCns means occupational categories of non-slum people; and INCns means the monthly income of non-slum people.

\section{Methods}

\section{Research design and measurement of variables}

The study follows explanatory sequential mixed method approach. The first step of the study is pre-test pilot survey through which the study conducts confirmatory factor analyses and checks the internal consistency, reliability and validity of data.

The second step is also quantitative in nature that follows the perfectly experimental research design. In this viewpoint, we used structured questionnaire to collect data on the new respondents. The respondents interviewed for pre-test were not included in the main survey. To test the proposed hypothesized models, the study considered four constructs SES, MOBIN, PGI and PBGI regarding COVID-19. The indicators of exogenous construct SES (education, occupation and income) were primarily used for constructing MOBIN and then for measuring PGI and PBGI regarding COVID-19 among the slum and non-slum people of the study area. Though the data on demographic variables were collected for understanding the characteristics of the respondents, the hypothesized model did not include them for not being significant in the pre-test survey. The SES has been defined as the socio-economic status for the slum or non-slum people based on the aggregate index score formed from their education, occupation and income. The levels of educational status were coded as Below JSC (including illiterate) $=1, S S C=2, H S C=3$, graduate $=$ 4, postgraduate $=5$, MPhil $=6$ and PhD and above $=7$. On the other hand, occupational status has been operationalized with the occupational levels adopted from the Quarterly Labor Force Survey 2017 with modification of codes considering the rank scores and the category others. In this viewpoint, occupational levels were coded as Inferior Occupation=1, Elementary Occupations=2, Plant and Machine Operators, and Assembler= 3, Craft and Related Trades Workers $=4$, Skilled Agricultural, Forestry and Fisheries= 5, Service and Sales Workers $=6$, Clerical Support Workers $=7$, Technicians and Associate Professionals $=8$, Professionals $=9$ and Managers $=10$. The income levels were classified into Below $10000=1,11000-30000=2,31000-50000=3$ and Above $50000=4$. Based on education, occupation and income, mobility index of non-slums divided by slums (MOBnss) was calculated in Statistical Package 
for the Social Sciences software (Windows version 25) using the following equation which was finally linked to Smart PLS software (Windows version 3.3) as MOBIN:

MOBnss $=(E D U n s / E D U s) *(O C C n s / O C C s) *(I N C n s / I N C s) *(1 / 3)$

Following the same equation, perception gap index of non-slum and slum people (PGInss) was calculated as a function of perceived susceptibility (SUSns for non-slum and SUSs for slum people), perceived severity (SEVns for non-slum and SEVs for slum people), perceived benefits (BENns for nonslum and BENs for slum people), perceived barriers (BARns for non-slum and BARs for slum people) and perceived self-efficacy (EFFns for non-slum and EFFs for slum people). Each of these indicators except perceived barriers were coded as Not at all $=1$, Seldom $=2$, Moderate $=3$, Quite $=4$ and Absolutely $=5$. On the other hand, the codes and scores of perceived barriers were reversal considering the negative action. The equation of PGInss was calculated in SPSS software and linked to SmartPLS software as PGI (Eq. 2).

$P G I n s s=($ SUSns $/ S U S s) *($ SEVns/SEVs $) *(B E N n s / B E N s) *(B A R n s / B A R s) *(E F F n s / E F F s) *(1 / 5)$

Similarly, the PBGInss regarding COVID-19 was calculated in SPSS and linked to Smart PLS as PBGI COVID-19 which was measured with 10 indicators such as PBat (How often do you avoid touching eyes, nose and mouth?), PBbe (How often do you bent elbow or tissue when you cough or sneeze?), PBdh (How often do you disinfect your home?), PBfm (How often do you wear facial mask in public venues?), PBhg (How often do you wear hand gloves while touching dirty/suspected things?), PBhq (How often do you maintain home quarantine if you feel unwell and isolate the affected person?), PBhs (How often do you clean your hands with an alcohol-based hand rub?), PBhv (How often do you maintain household ventilation?), PBsd (How often do you maintain at least 1-meter (3 feet) distance?) and PBsh (How often do you stay home if you feel unwell?). These 10 indicators of PBGI regarding COVID-19 were measured through 5 level scales and coded as Never= 1 , Seldom $=2$, Sometimes $=3$, Often $=4$ and Almost always= 5. The equation of PBGInss was calculated in Statistical Package for the Social Sciences (SPSS) software and linked to Smart PLS software as PBGI (Eq. 3).

$P B G / n s s=(F M n s / F M s) *(H S n s / H S s) *(S D n s / S D s) *(H V n s / H V s) *(D H n s / D H s) *(S H n s / S H s) *(H G n s / H G s) *$ (ATns/ATs)*(HQns/HQs)*(ETns/ETs)*(1/10)

In the third step, the study follows qualitative technique of data collection to explore other extraneous factors that can explain the preventive behaviors of slum and non-slum people of Bangladesh regarding COVID-19. In this regard, 10 Key Informant Interviews (KIIs) from slum and 10 KIls from non-slum people were conducted.

\section{Sampling technique, sample size determination and data collection}

Purposive sampling techniqe has been used to conduct this study for considering the very purpose of the study and selecting the relevant respondents who can provide the required information for conducting the 
study. Accordingly, the data has been collected from 100 slum people and 100 non-slum people of Mirpur area in Dhaka city. The reason of selecting Mirpur area as the sample respondents considering the availability of both types of respondents (i.e., slum and non-slum people coming of affluent families). To collect the data from affluent non-slum people, the study has selected DOHS area. On the other hand, for collecting the data from slum people, the study selected 5 slums of Mirpur including Jhilpar Slum of Mirpur 7, Kalshi Slum of Mirpur 11, Alokdi Slum of Mirpur 12, Slum beside Mirpur DOHS and Takerhat Slum considering the danger zones of COVID-19 infections.

The previous studies following Smart PLS to develop structural equation model suggested that a sample size ranging from 100 to 200 was usually a standard starting point in carrying out path modeling [18]. The present study has determined a sample size of 200 (100 from slum people and 100 from non-slum affluent families). The formula for determining sample size was not used since the study adopted purposive sampling technique.

For the proper empirical investigation, a pre-test survey was conducted by us. 10 respondents from slum areas and 10 from non-slum affluent families were requested to participate in this pre-test survey. After successfully completing that pre-test, we moved forward to carry out final survey. Respondents of pre-test were not included in the final survey. The survey was conducted in Mirpur area from 25 June to 20 July 2021. While collecting data, appropriate sampling procedure was followed in order to avoid the sampling error. In this regard, all survey interviews were conducted by a group of trained data collectors. All respondents were explained the significance and implication of the present study. The interview of each respondent was taken care of for a long time. The data collectors did not indulge in any personal and irrelevant gossiping to avoid anchoring or influencing the answers of the respondents. The survey strictly followed data collection protocols subject to maintaining compliance with human research. In addition, 20 KIls (10 from slum and 10 from non-slum people) were also conducted since the study follows the explanatory sequential mixed method approach.

\section{Results}

The study found the whole sample as to be skewed towards greater representation of individuals with diversified education, occupation and income including demographic variables. Table 1 shows the distribution of socio-demographic and socio-economic status characteristics of the respondents.

In terms of demographic characteristics, about 50 percent of the respondents among slums and 40 percent among non-slums lie in the oldest category (above 40). With regard to gender, 50 percent respondents are female and the remaining 50 are male among both type of respondents. In terms of ethnicity, 96 percent of the respondents are found to be Bengali among slums and 90 percent among non-slums. Similarly, 87 percent of the respondents are found to be Muslims among slums and 92 percent among non-slums.

With regards to the characteristics of SES, a greater 77 percent of slum people could not pass Junior School Certificate(JSC), whereas 56 percent of the non-slum people have obtained the post-graduate level 
degree followed by 30 percent graduate level degree. Occupational statuses of slum people are also absolutely downward while the non-slum people are found to be quite upward in occupational mobility. The highest 89 percent of slum people lie in the lowest income category (i.e., below Tk. 10000 or US\$.119.04) while the 59 percent of the non-slum people lie in the income category Tk. 31000-50000 (US\$. 369.05-595.23) followed by 22 percent of them who lie in the category Tk. 11000-30000 (US\$. 130.95-357.14). For better empirical assessment, we developed the measurement model and structural model for measuring the endogenous and exogenous constructs.

\section{Table 1.}

\section{Measurement model}

In order to measure the hypothesized model, the study follows three steps. First of all, the internal consistency of the exogenous construct 'SES NON-SLUM' is evaluated through Cronbach's Alpha and composite reliability (CR). The study finds that all the values are much higher than the threshold value of 0.50 . Whereas, the internal consistency of the exogenous construct 'SES SLUM'was not confirmed according to Cronbach's Alpha, Composite Reliability (CR) and Average Variance Extracted (AVE) though rho_A confirms the internal consistency of SES SLUM'. Despite such limitation, the internal consistency of data has been confirmed considering the purpose of developing structural equation model comparing between slum and non-slum people and avoiding to discard the construct SES SLUM'.

Secondly, the convergent validity has been checked through cross-loadings (Fig. 2) and average variance extracted (AVE) where both values should have greater than the acceptable threshold of $0.50[19,20]$. The cross-loadings of EDUns (0.936), INCns (0.954) and OCCns (0.990) and EDUs (-0.477), INCs (-0.274) and OCCs (0.969) of our study imply that respectively SES of non-slum people have enough reflection on their SES, while EDUs and OCCs have negative reflection on their SES though OCCs has enough reflection. Though EDUs and INCs should be deleted according to the law of factor analysis, they have been kept in the measurement model in order to compare among the SES of non-slum and slum people. The cross-loadings and AVE values greater than 0.50 in our study confirm the convergent validity of our data and the values less than the threshold level has been kept in the model considering the purpose of developing structural equation model comparing between slum and non-slum people.

Finally, the discriminant validity has been evaluated through Heterotrait-Monotrait (HTMT) ratio which should be less than 0.90 [21]. On the other hand, [22] argue that it should be less than 0.85 . Our estimated HTMT ratios of SES NON SLUM, SES SLUM, MOBIN, PGI and PBGI are lower than 0.85 that make conformity of discriminant validity of data.

\section{Structural Model}

The structural model signifies the inner models where there are relationships between exogenous and endogenous constructs $[23,24]$. To evaluate the structural model, the study follows few steps. First of all, multicollinearity has been checked. The estimated values of the variance inflation factor (VIF) ensure that 
the constructs of the model are fairly free from multicollinearity problem since most of the VIF of lesser than 3 and three factors are beyond 5 [19].

Secondly, in terms of coefficient effect, the exogenous construct SES of slum people has negative effects on all the constructs such MOBIN (-0.206), PGI (-0.011) and PBGI (-.022) regarding COVID-19. On the other hand, the exogenous construct SES of non-slum people has positive effects on MOBIN (0.902) and PGI (0.545) but negative effect on PBGI (-0.143). The negative effects of SES among slum people imply that the slum people experience downward mobility while the positive effects of SES among non-slum people imply that the slum people experience upward mobility. However, the high SES of non-slum people have no direct significant effect on their PBGI regarding COVID-19. Rather, their SES has significant effect on PBGI mediated through MOBIN and PGI. These effects mean that the gap of SES between slum and nonslum people plays key role in increasing further perception gap and preventive behavior gap among them. The existing studies also predicts such effect of SES index on health beliefs and the likelihood of action or preventive behavior [11]. The study also shows that all the structural path coefficients between SES among slum people have been found to be non-significant at 5 percent level with the T-statistics lesser than 1.96 and $P$ values greater than 0.05 . By contrast, though the structural path relationship between SES of non-slum people and PBGI regarding COVID-19 is not directly significant, their SES has a mediated effect through MOBIN and PGI because of their greater T-statistics than 1.96 and lesser P-value than 0.05 . However, $\mathrm{PGI}$ is found to be the strongest predictor of PBGI where the main contributor is SES of non-slum people (Table 2 and Fig. 3 ).

Thirdly, the coefficient of determination $\left(R^{2}\right)$ value (0.933) which explains the explanatory power of model indicates that $93.3 \%$ of the variation of the endogenous latent variable PBGI is explained by the associated exogenous SES of slum and non-slum people mediated through PGI which is directly influenced by SES of non-slum and slum people and also mediated through PGI. Since the PBGI value exceeds 0.67 , the model is strongly explained by both its positive and negative predictors. Thus, the hypothesized model is acceptable.

Fourthly, the effect size $\left(f^{2}\right)$ is another instrument where it is possible to assess the effect size of exogenous constructs on the endogenous constructs. According to [25], the effect sizes of $0.02,0.15$ and 0.35 represent respectively small effect, medium effect and large effect of exogenous on endogenous constructs. The present study reveals that the construct SES NON-SLUM has directly large effect on MOBIN (2.14) and the largest mediated effect (SES NON-SUM*PGI) on PBGI (8.415) regarding COVID-19. It should be noted that the construct SES NON-SLUM has small effect on PBGI (0.131). By contrast, the construct SES SLUM has very negligible effect on PBGI (0.006) and no effect on PGI while the construct has small effect on MOBIN (0.112). But, due to the negative structural coefficient effect, such SES effect of slum people indicates the negative effect on MOBIN.

Finally, based on the Blindfolding method, estimated predictive power or relevance of endogenous construct $\left(\mathrm{Q}^{2}\right)$ ensures that $\mathrm{PBGI}$ regarding COVID-19 has a strong predictive power and relevance since the $Q^{2}$ value is 0.921 that is greater than the threshold value of 0 . This estimated value is consistent with 
the suggested $Q^{2}$ value of the Stone-Geisser model $[26,27]$. This $Q^{2}$ value indicates the model has strong predictive capacity and relevance in the study context.

\section{Discussion}

Since the study follows the explanatory sequential mixed method approach, in the final step the study explores the open views of the slum people regarding their health perception and preventive behavior regarding COVID-19. The reason is that through this qualitative insight from the disadvantaged groups can help the social researchers to revisit the HBM and to find out the influential factors that can explain the poverty stricken people of our country. In this regard, 10 key informants from slum people and 10 key informants from non-slum people were interviewed.

The affluent non-slum people who are highly educated, occupationally prestigious and belonged to upper class in terms of earning can perceive that they are susceptible to be infected with COVID-19. They can also perceive severity of COVID-19, benefits of preventive behaviors and self-efficacy regarding preventive action. They do not have negativity (barriers) of maintaining preventive measures. By and large, they try to follow the instructions of medical practitioners as evident from the quantitative results of the study. The strongest factor of affluent families is their education. For example, when they were asked about the reason of their perception of the severity of COVID-19 and preventive behavior regarding it, one of the key informants put it:

What we see in the society is that the more you educated, the more you earn through occupations. The individuals who have higher education, they can get the high level job. And job facilities and their earnings lead them to aware of the health risks and thus they try to prevent themselves from risk behavior.

Our study finds the non-slum affluent families as to be upward in social mobility. However, the slum people were found to be downward in all respects.

Most of the slum people were downward in terms of education, occupation and income as evident from the quantitative findings. The qualitative results were also consistent with the quantitative one in line with their perception and preventive behaviors regarding COVID-19.

The slum people are neither afraid of the severity of COVID-19 nor have perception regarding the possibility of their infection. As one of the key informants put it:

Corona virus disease is not for us. I think, I am not at risk of coronavirus disease. I heard and see in television that coronavirus disease leads to death, but I don't see. I am reluctant about COVID-19.

Another informant says:

There is no benefit of wearing masks, using hand sanitizers or following other instructions given by doctors or health organizations. Rather, we have heard that due to receiving vaccine against COVID-19, 
many people have died.

One Hujur (religious leader) who is the slum dweller puts interesting observation:

Corona virus is the Ajab (punishment) from Allah. Because, we have forgotten our creator. We are much more involved in crimes and offences than the past. So, Allah is teaching us and warning us to be corrected. But we are not correcting ourselves. So, corona virus is being continued. I think, if we cannot understand our offences and are not serious to prevent from bad deeds, this punishment from Allah will be continued.

Among the preventive measures regarding COVID-19, wearing masks is the common trend among most of the slum dwellers. However, they do not use surgical masks, but masks made of different fabrics. It should be noted that they usually do not wear mask. They wear mask in restricted places like cantonment or check post. One of the respondents said "I earn very little money by driving a rickshaw. We all can't afford surgical mask. We can wash and use the cloth-masks again and again. Hand sanitizer and safety kit is a luxury goods in slum area. This is their reality that they must live from hand to mouth. In terms of using hand sanitizer, most of them put it "We didn't use hand sanitizer. Even, we had no knowledge about it. But when World Vision provided Hexisol Hand Rub for us, then we began to use it."

Slum houses were like box having no windows. When they were asked if they maintain household ventilation, one of the key informants, described the situation saying that:

"The ventilation process takes place on its own. They do not have that luxury to afford window or any ventilation system in their houses. Only the door is the way of the wind flow in their houses. Even, we do not have adequate access to light and air."

Social distancing is another barrier of the slum people. They could not maintain at least one-meter distance apart from each other. Every house is very small and one family lives in only one room. As a result, there is no scope for quarantine in a separate room if someone is infected with COVID-19. Due to the financial crisis and extreme poverty, they cannot disinfect their houses and surroundings. Similarly, they cannot use tissues or handkerchiefs while coughing or sneezing. One of key informants put it:

"Most of the time in a day, my family is starving for living from hand to mouth. Then, how can I buy facial masks, hand-sanitizers or other costly items for preventing from COVID-19 infection. You can tell our government to provide these items free and rehabilitate us with modern facility-based housing. Then we can follow all the instructions regarding COVID-19. For example, we are taking vaccine since vaccines are given free."

Interestingly, when the Hujur was asked that will you take vaccine? He replied yes and argued that it is free. He also added that both Dua (prayers) and Dawah (medicine) are important for Shifa (cure from disease). 
Despite rigorously following the scientific methods, the present study has some limitations. The first limitation is to conduct the study based on the respondents of only one area of Bangladesh, using purposive sampling considering the very purpose of the study and limited budget. However, if the number of sample areas were expanded, the study findings would have been more nationally representative. In this regard, the future researchers are recommended for expanding the larger sample size including the different areas of Bangladesh. To do so, the researchers are recommended to conduct such study having necessary fund. The second limitation is to explain $P B G /$ from social mobility theory and HBM though there are many other health seeking behavior models such as theory of reasoned action, ecological model etc. The third limitation of the study is not to predict the COVID-19 related preventive behavior among religious and non-religious people in Bangladesh since religion matters the pandemic that is empirically grounded. The final limitation is to include only SES mobility developed by [11] though there are some other aspects of SES mobility (e.g., CAPSES aspect where SES is defined as a function of three capital factors such as Human Capital, Material Capital and Social Capital). Furthermore, the future researchers are recommended to conduct the research in the field of health perception gap index and preventive behavior gap index regarding COVID-19 depending on the CAPSES factors developed by [28].

\section{Conclusions}

The general objective of the study is to understand the effect of the Intragenerational social mobility among slum and non-slum people on PBGI regarding COVID-19. This is the first study to explain and predict the PBGI in the social mobility context of Bangladesh. The quantitative study findings reveal that upward SES of non-slum affluent families in Bangladesh has strong mediating effect (SES NONSLUM*PGI) on PBGI regarding COVID-19. Thus, the upward SES mobility of non-slum people increases the unequal health perception and preventive behavior regarding COVID-19 in the society. On the other hand, the downward SES mobility of slum people leads them to lie in the false perception and the risk behavior regarding COVID-19. This result has been consistent with that of [11] in their study on "Occupational Structure in America". But, when they were asked through open questions using qualitative approach, the facts became clearer suggesting that only SES based on education, occupation and income differs the perception index and preventive behavior index of the slum and non-slum people regarding COVID-19.

However, based on the estimated results and the qualitative insights, this study has some implications for the policy makers of our government as well as the medical sociologists and psychologists. First of all, the policy makers and government should take proper steps to boost up the mobility and increasing universalism without compromising the slum or destitute people who live from hand to mouth. Secondly, administrators should prioritize the educational and occupational aspects of all groups and communities of Bangladesh since these three indicators are the key role maker of unequal health perception and preventive behavior regarding COVID-19 in Bangladesh. Thirdly, the government should provide free equipment for the disadvantaged people like slum dwellers who live from hand to mouth. Fourthly, medical sociologists should revisit HBM adding with another socioeconomic factor 'free provision of protective equipment'. Finally, social scientists should conduct further studies in this field to 
move from the 'Intragenerational social mobility, PGI, and PBGI regarding COVID-19 in Bangladesh' to the social mobility and health inequality.

\section{Declarations}

\section{Availability of data and materials}

The datasets used during the current study are available from the corresponding author on reasonable ground and request.

\section{Abbreviations}

AVE: $\quad$ Average Variance Extracted

COVID-19: Coronavirus Disease 2019

CR: $\quad$ Composite Reliability

HBM: $\quad$ Health Belief Model

HSC: $\quad$ Higher Secondary Certificate

IEDCR: Institute of Epidemiology, Disease Control and Research

JSC: Junior School Certificate

KAP: $\quad$ Knowledge, Attitude and Practice

MOBIN: Mobility Index

MPhil: $\quad$ Master of Philosophy

PBGI: $\quad$ Preventive Behavior Gap Index

PGI: $\quad$ Perception Gap Index

PhD: $\quad$ Doctor of Philosophy

PLS: $\quad$ Partial Least Square

SARS-CoV-2: Severe Acute Respiratory Syndrome, Coronavirus 2

SES: $\quad$ Socioeconomic Status

SPSS: $\quad$ Statistical Package for the Social Sciences 
SSC: $\quad$ Secondary School Certificate

VIF: $\quad$ Variance Inflation Factor

\section{References}

1. Ruan Q, Yang K, Wang W, Jiang L, Song J. Clinical predictors of mortality due to COVID-19 based on an analysis of data of 150 patients from Wuhan, China. Intensive Care Medicine. 2020; 46: 846-848.

2. New Age. (2020, March 5) Bangladesh at high risk of coronavirus. 2020, March 5. Available from https://www.newagebd.net/article/101292/bangladesh-at-high-risk-of-coronavirus.

3. Ferdous MZ, Islam MS, Sikder MT, Mosaddek MAS, Zegarra-Valdivia JA, Gozal D. Knowledge, attitude, and practice regarding COVID-19 outbreak in Bangladesh: An online-based cross-sectional study. PLOS ONE. 2020; 15: e0239254.

4. Hossain MJ. Impact of COVID-19 Pandemic among health care providers in Bangladesh: A systematic review. Bangladesh Journal of Infectious Diseases. 2020; 7: S8-S15.

5. Hossain MJ, Kuddus, MR, Rahman SMA. Knowledge, attitudes, and behavioral responses toward COVID-19 during early phase in Bangladesh: A questionnaire-based study. Asia Pacific Journal of Public Health. 2021; 33:141-144.

6. Chen Y, Zhou R, Chen B, Chen H, Li Y, Chen Z, Zhu H, Wang H. Knowledge, perceived beliefs, and preventive behaviors related to COVID-19 among Chinese older adults: Cross-sectional web-based survey. Journal of Medical Internet Research. 2020; 22: e23729.

7. Kamate SK, Agrawal A, Chaudhary H, Singh K, Mishra P, Asawa K. Public knowledge, attitude and behavioural changes in an Indian population during the Influenza $A(\mathrm{H} 1 \mathrm{~N} 1)$ outbreak. The Journal of Infection in Developing Countries. 2009; 4: 007-014.

8. Liao Q, Cowling B, Lam WT, Ng MW, Fielding R. Situational Awareness and Health Protective Responses to Pandemic Influenza A (H1N1) in Hong Kong: A Cross-Sectional Study. PLOS ONE, 2010; 5: e13350.

9. Carpenter CJ. A meta-analysis of the effectiveness of health belief model variables in predicting behavior. Health Communication. 2010; 25: 661-669.

10. Lau JTF, Griffiths S, Au DWH, Choi KC. Changes in knowledge, perceptions, preventive behaviours and psychological responses in the pre-community outbreak phase of the H1N1 epidemic. Epidemiology and Infection. 2011; 139: 80-90.

11. Blau PM, Duncan OD, Tyree A. The American occupational structure. New York:Wiley, 1967. 
12. Rosenstock IM, Strecher VJ, Becker MH. Social learning theory and the health belief model. Health Education Quarterly. 1988; 15, 175-183.

13. Harrison JA, Mullen PD, Green LW. A meta-analysis of studies of the health belief model with adults. Health Education Research. 1992; 7: 107-116.

14. Jones CJ, Smith H, Llewellyn C. Evaluating the effectiveness of health belief model interventions in improving adherence: A systematic review. Health Psychology Review. 2014; 8: 253-269.

15. Janz NK, Becker MH. The health belief model: A decade later. Health Education Quarterly. 1984; 11(1): $1-47$.

16. Jones CJ, Smith H, Llewellyn C. Evaluating the effectiveness of health belief model interventions in improving adherence: A systematic review. Health Psychology Review. 2014; 8: 253-269.

17. Amanullah ASM, Uddin J. Dynamics of health behavior regarding hospital waste management in Dhaka, Bangladesh: A dysfunctional health belief model. International Quarterly of Community Health Education. 2010; 29: 363-380.

18. Hoyle RH. Structural equation modeling: Concepts, issues, and applications. California: Sage Publications, 1995.

19. Hair FJ, Sarstedt M, Hopkins L, Kuppelwieser, GV. Partial least squares structural equation modeling (PLS-SEM): An emerging tool in business research. European Business Review. 2014; 26: 106-121.

20. Hair JF. Multivariate data analysis with readings. New Jersey Prentice Hall, 1995.

21. Gold AH, Malhotra A, Segars AH. (2001). Knowledge management: An rganizational capabilities perspective. Journal of Management Information Systems. 2001; 18: 185-214.

22. Benitez J, Henseler J, Castillo A, Schuberth F. (2020) How to perform and report an impactful analysis using partial least squares: Guidelines for confirmatory and explanatory IS research. Information \& Management. 2020; 57: 103168.

23. Hair JF (2010). Multivariate data analysis. New Jersey: Prentice Hall, 2010.

24. Henseler J, Ringle CM, Sarstedt M. Using partial least squares path modeling in advertising research: Basic concepts and recent issues. Handbook of Research on International. 2012. Available from https://www.elgaronline.com/view/edcoll/9781848448582/9781848448582.00023.xml.

25. Cohen J. Statistical power analysis for the behavioral sciences. Lawrence Erlbaum: Hillsdale, 1988.

26. Geisser S. A predictive approach to the random effect model. Biometrika. 1974; 61: 101-107. 
27. Stone M. Cross-validatory choice and assessment of statistical predictions. Journal of the Royal Statistical Society: Series B (Methodological). 1974; 36: 111-133.

28. Oakes JM, Rossi PH. The measurement of SES in health research: Current practice and steps toward a new approach. Social Science \& Medicine. 2003; 56: 769-784.

\section{Tables}

Table 1. Demographic and SES characteristics of respondents 


\begin{tabular}{|c|c|c|c|c|}
\hline \multirow[t]{3}{*}{ Variables } & \multicolumn{4}{|c|}{ Distribution of the respondents } \\
\hline & \multicolumn{2}{|l|}{ Slum } & \multicolumn{2}{|l|}{ Non-slum } \\
\hline & Frequency & $(\%)$ & Frequency & $(\%)$ \\
\hline \multicolumn{5}{|l|}{ Age } \\
\hline $31-35$ & 17 & 17.00 & 18 & 18.00 \\
\hline $36-40$ & 35 & 35.00 & 43 & 43.00 \\
\hline$>40$ & 48 & 48.00 & 39 & 39.00 \\
\hline \multicolumn{5}{|l|}{ Gender } \\
\hline Female & 50 & 50.00 & 50 & 50.00 \\
\hline Male & 50 & 50.00 & 50 & 50.00 \\
\hline \multicolumn{5}{|l|}{ Ethnicity } \\
\hline Bengali & 96 & 96.00 & 90 & 90.00 \\
\hline Others & 4 & 4.00 & 10 & 10.00 \\
\hline \multicolumn{5}{|l|}{ Religion } \\
\hline Hindus & 9 & 9.00 & 4 & 4.00 \\
\hline Islam & 87 & 87.00 & 92 & 92.00 \\
\hline Others & 4 & 4.00 & 4 & 4.00 \\
\hline \multicolumn{5}{|l|}{ Education } \\
\hline$<P S C$ & 77 & 77.00 & 0 & 0.00 \\
\hline JSC & 14 & 14.00 & 0 & 0.00 \\
\hline SSC & 5 & 5.00 & 6 & 6.00 \\
\hline HSC & 4 & 4.00 & 7 & 7.00 \\
\hline Graduate & 0 & 0.00 & 30 & 30.00 \\
\hline Postgraduate & 0 & 0.00 & 56 & 56.00 \\
\hline MPhil & 0 & 0.00 & 1 & 1.00 \\
\hline $\mathrm{PhD}$ & 0 & 0.00 & 0 & 0.00 \\
\hline \multicolumn{5}{|c|}{ Income category } \\
\hline$<$ Tk. 10000 & 89 & 89.00 & 5 & 5.00 \\
\hline $11000-30000$ & 11 & 11.00 & 20 & 20.00 \\
\hline $31000-50000$ & 0 & 0.00 & 59 & 59.00 \\
\hline
\end{tabular}




\begin{tabular}{|lllll|}
$>$ Tk. 50000 & 0 & 0.00 & 16 & 16.00 \\
Occupation & & & & \\
Inferior Occupation & 47 & 47.00 & 6 & 6.00 \\
Elementary & 33 & 33.00 & 0 & 0.00 \\
Plant and Machine Operators \& Assemblers & 20 & 20.00 & 0 & 0.00 \\
Craft and Related Trades Workers & 0 & 0.00 & 0 & 0.00 \\
Skilled Agricultural, Forestry and Fisheries & 0 & 0.00 & 5 & 5.00 \\
Service and Sales Workers & 0 & 0.00 & 4 & 4.00 \\
Clerical Support Workers & 0 & 0.00 & 13 & 13.00 \\
Technicians and Associate Professionals & 0 & 0.00 & 16 & 16.00 \\
Professionals & 0 & 0.00 & 46 & 46.00 \\
Managers & 0 & 0.00 & 10 & 10.00 \\
& & & & \\
\hline
\end{tabular}

Table 2. Results of estimated path coefficients

\begin{tabular}{|llll|}
\hline & Coefficients & T Statistics & P Values \\
\hline MOBIN -> PGI & 0.24 & 1.451 & 0.147 \\
\hline PGI -> PBGI_Covid19 & 1.066 & 33.887 & 0.000 \\
\hline SES_NON_SLUM -> MOBIN & 0.902 & 14.062 & 0.000 \\
\hline SES_NON_SLUM -> PBGI_Covid19 & -0.143 & 3.123 & 0.002 \\
\hline SES_NON_SLUM -> PGI & 0.545 & 3.866 & 0.000 \\
\hline SES_SLUM -> MOBIN & -0.206 & 1.795 & 0.073 \\
\hline SES_SLUM -> PBGI_Covid19 & -0.022 & 0.680 & 0.497 \\
\hline SES_SLUM -> PGI & -0.011 & 0.121 & 0.904 \\
\hline
\end{tabular}


Figures

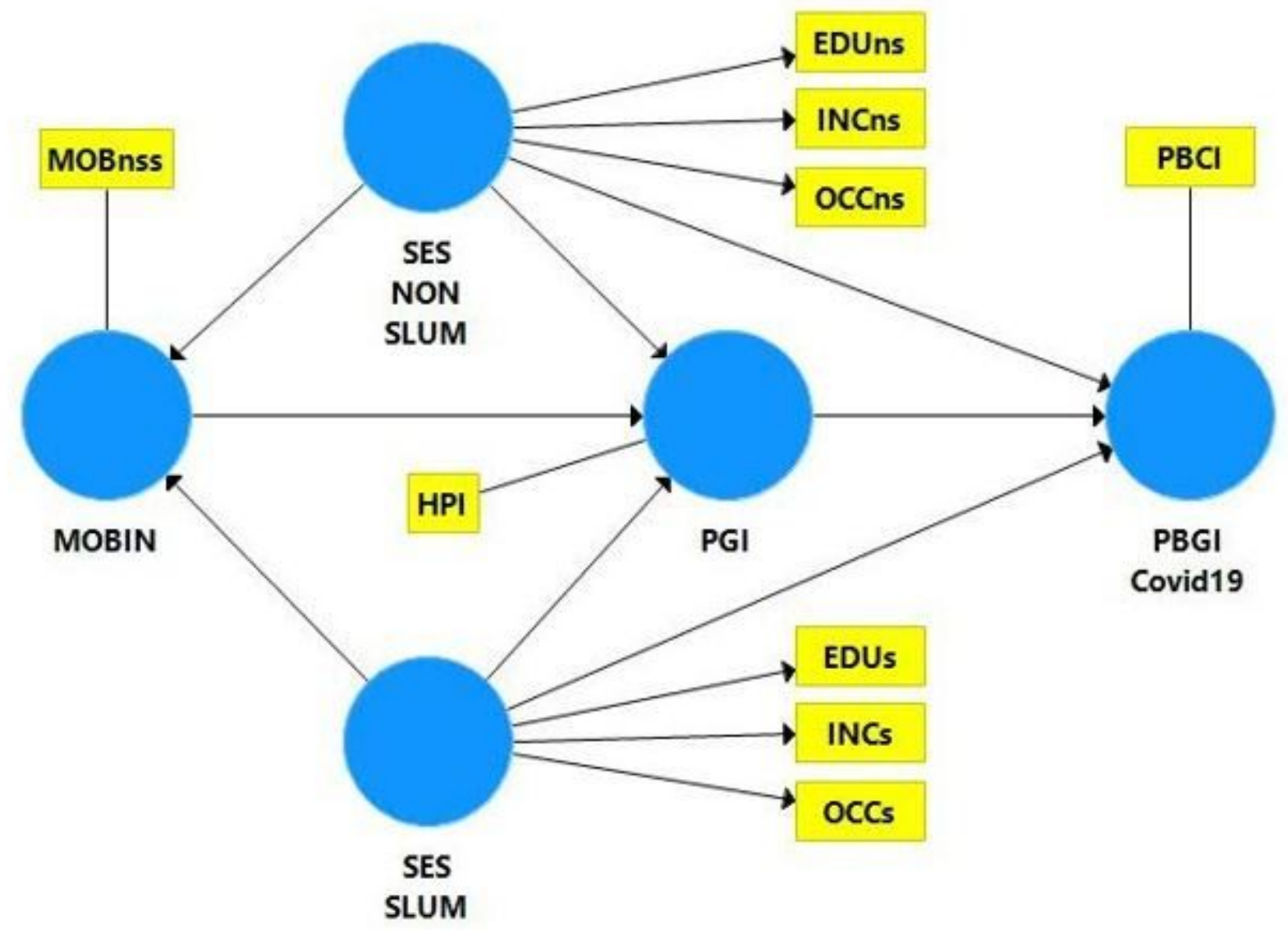

Figure 1

Hypothesized model of slum and non-slum peoples regarding COVID-19 


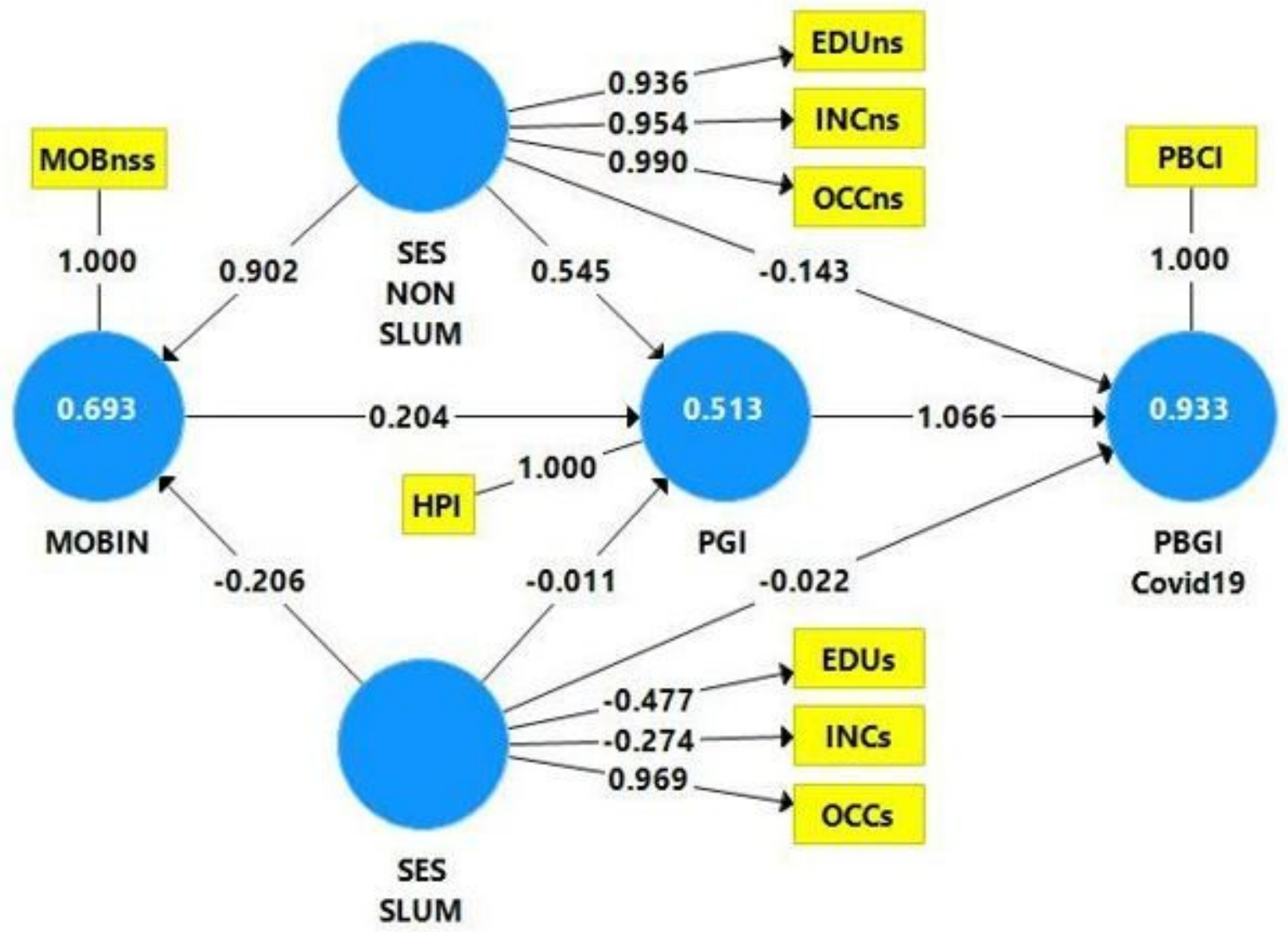

Figure 2

Measurement model 


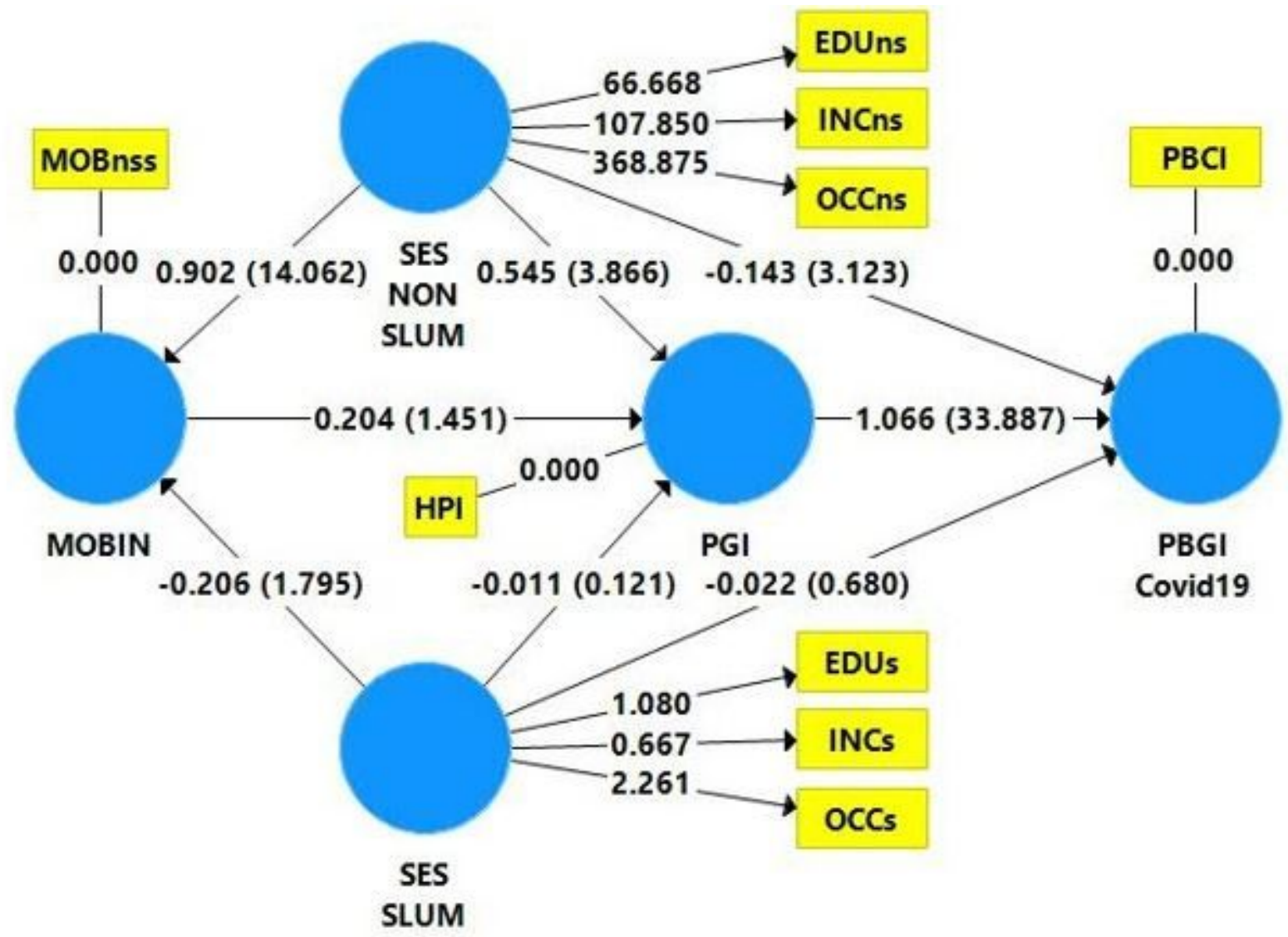

Figure 3

Structural path coefficients and T-statistics 